\title{
EL ESTATUTO TRAS LA SENTENCIA
}

\author{
ENRIC FOSSAS ESPADALER \\ Catedrático de Derecho Constitucional \\ Universitat Autònoma de Barcelona
}

\begin{abstract}
SUMARIO
I. Introducción

II. Los planteamientos de las partes

III. Los razonamientos jurídicos de la Sentencia

IV. El modo de aplicación de las «consideraciones de principio» al contenido del EAC 2006.

V. Conclusiones
\end{abstract}

\section{INTRODUCCIÓN}

Decía el Juez Burger, antes de convertirse en Presidente del Tribunal Supremo americano, que un Tribunal «último e inapelable» necesita un escrutinio más intenso que cualquier otro ya que en una democracia ninguna institución pública, ni aquéllos que la integran, pueden estar por encima del debate público ${ }^{1}$. Como toda decisión que proviene de un poder público, la Sentencia del Tribunal Constitucional sobre el nuevo Estatuto de Autonomía de Cataluña debe pues someterse al examen de la opinión pública y también a la de los analistas políticos y jurídicos, que a mi juicio han de valorarla por su proceso de adopción, por su resultado y por sus consecuencias.

No es necesario señalar aquí la trascendencia de esta resolución, que ha llegado a ocupar el centro de la vida política española, ha monopolizado la actividad del Tribunal durante meses, y se ha considerado el reto más importante al que aquél se habrá enfrentado en sus primeros treinta años de historia. De esa trascendencia, sin embargo, no de-

1 Las palabras exactas de WARREN E. BURGER fueron: «A court which is final and unreviewable needs more careful scrutiny than any other. Unreviewable power is the most likely to self-indulge itself and the least likely to engage in dispassionate self-analysis...In a country like ours, no public institutions, or the people who operates it, can be above debate». Con esta cita se inicia el popular libro de los periodistas Woodward, B. - Armstrong, S., The brethren. Inside the Supreme Court, Avon Books, New York, 1981. 
rivan necesariamente grandes repercusiones, y solo con el tiempo dispondremos de la perspectiva necesaria para comprobar los efectos reales que habrá producido.

Desde luego, escapa ampliamente a los propósitos de esta contribución realizar una valoración general de la Sentencia: ni de su proceso de elaboración y adopción, ni de sus pronunciamientos en relación con los objetivos políticos y jurídicos perseguidos por el nuevo Estatuto catalán, ni de las previsibles o posibles consecuencias que vaya a entrañar para la autonomía de Cataluña, y en general, para el futuro desarrollo del Estado Autonómico. Ciertamente, todo ello no puede ser ignorado al examinar cualquier aspecto de la STC 31/2010, de 28 de junio, que resuelve el recurso de inconstitucionalidad interpuesto por 99 Diputados del Grupo Parlamentario Popular del Congreso contra diversos preceptos de la Ley Orgánica 6/2006, de 19 de julio, de reforma del Estatuto de Autonomía de Cataluña (EAC 2006). Pero el contenido de este trabajo, a pesar de que su título pueda inducir a equívocos, se limitará al estudio de la fundamentación de la Sentencia con el objetivo de valorar la doctrina que contiene sobre la naturaleza y función del Estatuto de Autonomía como fuente del Derecho que forma parte de nuestro ordenamiento jurídico ${ }^{2}$.

Esta es una cuestión de gran alcance porque, a mi juicio, la peculiaridad normativa del Estatuto de Autonomía es aquello que confiere peculiaridad al Estado Autonómico frente a otros modelos de organización territorial, en los que no existe una categoría equiparable $^{3}$. Y es sin duda la cuestión clave de la Sentencia, pues sobre la misma basaron los recurrentes buena parte de sus alegaciones, tal como se expresa en un primer apartado de su escrito de demanda en el que vierten unas «Consideraciones generales» (Antecedente 11), que según el propio Tribunal «inspiran el fundamento impugnatorio del conjunto del recurso», y cuyas razones «circunscriben el verdadero núcleo de la cuestión debatida a la definición de la función y contenido propios de los Estatutos de Autonomía; su po-

2 Este tema fue objeto de unos primeros comentarios por parte de los Profesores AlberTí Rovira, E,; Castellà Andreu, J. M; Tornos Mas, J.; y Fossas Espadaler, E., en la Revista Catalana de Dret Públic. Número especial sobre la STC 31/2010. Septiembre 2010. (http://www.rcdp.cat). En este mismo número puede consultarse un apéndice documental relacionado con el recurso de inconstitucionalidad del Grupo Popular contra el EAC 2006 y los incidentes procesales ocurridos durante su tramitación. El tema tratado en el presente artículo también se aborda en algunos de los comentarios aparecidos tras la Sentencia, y que figuran en la revista El Cronista del Estado Social y Democrático de Derecho, núm. 15, octubre 2010; en la revista Claves de Razón Práctica, núms. 206 y 206, septiembre y octubre 2010; en Diario La Ley (núm. 7489); y en la revista Activitat Parlamentària (número especial de septiembre 2010). En el momento de entregar esta contribución ha aparecido la primera monografía dedicada al análisis de la Sentencia: Tur Ausina, R.-Álvarez Conde, E., Las Consecuencias Jurídicas de la Sentencia 31/2010, de 28 de junio del Tribunal Constitucional sobre el Estatuto de Cataluña. La Sentencia de la Perfecta Libertad, Aranzadi-Thomson Reuters, Pamplona, 2010.

3 Como es conocido, la idea de basar la organización territorial del Estado en regiones que acceden a la autonomía política mediante un Estatuto propuesto por cada una de ellas, y aprobado como ley estatal, surgió con la Constitución de la Segunda República española de 1931, en la que se inspiró parcialmente la Constitución italiana de 1947. En las llamadas «regiones de Estatuto ordinario», éste podía equipararse a los Estatutos de las CCAA que accedieron a la autonomía por la vía de los arts. 143 y 146 CE. Sin embargo, las últimas reformas constitucionales han modificado aspectos esenciales de tales Estatutos, como el referido a su aprobación y reforma, que no requiere la intervención del Parlamento italiano (LC núm. 1 de 1999); así como el relativo a su contenido, que ya no incluye las competencias de la región pues es la Constitución la que incorpora un sistema de distribución de competencias de corte federal (LC num. 3 de 2001). Tales modificaciones alejan los actuales Estatutos ordinarios italianos de los Estatutos de Autonomía vigentes en nuestro ordenamiento. (Ver Prada Fernández, J. L., Las reformas constitucionales italianas, Dilex, Madrid, 2008, pág. 137 y ss.). 
sición, en definitiva, en el sistema de fuentes establecido en la Constitución y, particularmente, su relación con la Norma fundamental y con las restantes normas del Ordenamiento.» (FJ 1). En efecto, tal cuestión es crucial ya que se enfrenta a los límites materiales y sustantivos de una norma a la que la Constitución le atribuye un papel esencial en la configuración de nuestro Estado de las Autonomías; y por ello, «al enjuiciar el contenido de un Estatuto no solo se examina la adecuación a la Constitución de esta norma sino que también se fijan los principios básicos del Estado de las Autonomías» ${ }^{4}$.

Debe señalarse que el Tribunal Constitucional no había tenido hasta hoy muchas ocasiones de pronunciarse al respecto, al menos de forma directa, por una razón que explicó el que fuera su Presidente, el Profesor Pedro Cruz Villalón, del modo siguiente: «En la tradición de nuestra Constitución de 1978, de nuestra cultura constitucional, está arraigada la idea de que «los Estatutos se respetan»: es decir, se interpretan, por unos o por otros, pero no se les declara inconstitucionales, en un extremo u otro, mientras materialmente pueda evitarse. En todo caso no hay experiencia de declaración de la inconstitucionalidad de un Estatuto de Autonomía. Lo que hemos llamado «bloque de la constitucionalidad» ha venido siendo respetado» 5 .

Lo que sí existe es una mínima experiencia de control de la constitucionalidad de un Estatuto, aunque ninguna comparable a la que se lleva a cabo en la STC 31/2010. En realidad, no es ésta la primera resolución en la que el Tribunal Constitucional enjuicia un Estatuto de Autonomía pues las SSTC 89/1984, de 28 de septiembre, y 99/1986, de 11 de julio, ya lo hicieron, si bien solo abordaron aspectos menores del Estatuto de Autonomía de Castilla y León referidos a su territorio ${ }^{6}$. Quede aquí anotado como dato curioso que en ambas se trató muy sucintamente de la «reserva estatutaria», el núcleo de la cuestión que se plantea en la STC 31/2010, tal como se verá. No es tampoco la primera ocasión en la que el Tribunal se enfrenta a una reforma estatutaria, puesto que ello ya ocurrió en la más reciente STC 247/2007, de 12 de diciembre, que resolvió un recurso de inconstitucionalidad contra la Ley Orgánica 1/2006, de 10 de abril, de reforma del Estatuto de Autonomía de la Comunidad Valenciana. Como se recordará, se impugnaba entonces un solo precepto de la citada Ley Orgánica que consagraba un derecho de los valencianos al agua (art. 17.1), y el Tribunal entendió que las cuestiones planteadas por el recurso «se suscitan en relación con un Estatuto de Autonomía, norma que ocupa, sin duda una singular posición en nuestro sistema de fuentes» (...), lo que obliga a ponderar «la posición y función que tienen en él los Estatutos de Autonomía» (FJ 3), cuestión a la que dedicó

4 Tornos Mas, J.: «El Estatuto de Autonomía de Cataluña, y el Estado Autonómico, tras la Sentencia del Tribunal Constitucional 31/2010», El Cronista del Estado Social y Democrático de Derecho, núm. 15, 2010, pág. 18. El autor ya señaló durante las últimas reformas estatutarias que «el protagonismo constitucional de los Estatutos comporta que el alcance de su contenido pase a tener una importancia destacada.» (...) pues «nuestro Estado de las Autonomías es fruto de la Constitución más el ejercicio del poder estatuyente» («La reforma estatutaria. Un debate marcado por la posición constitucional de los Estatutos de Autonomía», Revista General de Derecho Administrativo, núm. 1, 2006, www.iustel.com).

5 Cruz Villalón, P.: «La reforma del Estado de las Autonomías», Revista d'Estudis Autonòmics i Federals, núm. 2, 2006, pág. 85

6 Ver Aguado Renedo, C.: «La jurisprudencia constitucional sobre la delimitación del ámbito territorial de Castilla y León» (I y II), Autonomies, núm. 11 (1989) y 14 (1992); Dí́z-PiCAzO, L.M.: «Sobre la delimitación estatutaria del territorio de las Comunidades Autónomas y la rigidez de los Estatutos (Comentario a la STC 99/1986, en el caso del Condado de Treviño)», Revista Española de Derecho Constitucional, núm. 20, 1987. 
los FFJJ 5 a 12 con el objetivo de determinar el contenido constitucionalmente legítimo de tales normas ${ }^{7}$.

La novedad de la STC 31/2010 en relación con las anteriores reside en las características del recurso que resuelve, «el primero con el que se impugna in extenso la reforma de un Estatuto de Autonomía, planteándose cuestiones de la mayor relevancia y trascendencia para la definición del modelo constitucional de distribución territorial del poder público» (FJ 1). Novedad en el aspecto cuantitativo del recurso, porque en la demanda se impugnan más de la mitad (136 artículos y disposiciones) del extenso articulado de un Estatuto (223 artículos, más las disposiciones finales y adicionales), además de su Preámbulo. Pero también en el aspecto cualitativo, por las razones que expresa el Tribunal y porque el recurso se dirige contra un «nuevo» Estatuto de Autonomía de Cataluña, completamente distinto al de 1979 en su forma y contenido, aprobado por el Parlamento de Cataluña y por las Cortes Generales, y refrendado por el cuerpo electoral de Cataluña, tras un largo y controvertido proceso político en el que por enésima vez fue objeto de debate una de las grandes, sino la principal, cuestión constitucional que tiene planteada el Estado español: la organización territorial del poder político y el otrora llamado «problema catalán». Un Estatuto redactado con ambiciosos objetivos políticos puesto que a partir de unos determinados planteamientos jurídicos pretendía incrementar sustancialmente y garantizar el autogobierno de Cataluña, lograr el reconocimiento de su identidad nacional diferenciada, establecer una posición singular de la Comunidad Autónoma dentro del Estado Autonómico, y mejorar su sistema de financiación.

Aún en este segundo aspecto no puede dejar de mencionarse el dilatado proceso constitucional seguido hasta dictarse la Sentencia, el cual se ha visto envuelto en unas conflictivas circunstancias políticas y jurídicas, como lo demuestran las múltiples vicisitudes acaecidas en el curso de su desarrollo, constatables en los mismos Antecedentes de la Sentencia y en un paciente repaso a las hemerotecas. Todo ello ha sumido al propio Tribunal Constitucional en una crítica situación institucional, sin duda la peor que ha vivido desde su creación, y ha convertido la Sentencia sobre el Estatuto catalán en una batalla política, mediática y jurídica, en la que han intervenido numerosos actores, y que ha hecho aflorar las peores pulsiones aún presentes en la precaria cultura constitucional española.

Como ya he avanzado, esta contribución no pretende realizar una valoración general de la Sentencia pues solo se propone examinar y comentar la doctrina que aquella contiene sobre la naturaleza y función del Estatuto de Autonomía como norma jurídica.

7 Un comentario sobre la misma puede verse en la sección «Doctrina del Tribunal Constitucional durante el tercer cuatrimestre de 2007», elaborada por ReQuejo Pagés, J. L.; DuQue Villanueva, J.C.; Torres Muro, I.; Fossas Espadaler, E., Revista Española de Derecho Constitucional, núm. 82, 2008, pág. 277 y ss.. En ese comentario se contempló la Sentencia sobre la reforma del Estatuto valenciano como un anticipo de la futura Sentencia sobre el nuevo Estatuto de Cataluña, pendiente entonces de resolución, pero la STC 31/2010 no ha seguido a la STC 247/2007, a la que apenas cita. Un análisis crítico de la STC 247/2007 se expone en Fernández Farreres, G., ¿Hacia una nueva doctrina constitucional del Estado Autonómico?, Thomson-Civitas, 2008. Algunos de los planteamientos contenidos en este trabajo fueron contestados por el Magistrado del Tribunal Constitucional, Manuel Aragón ReYes, en un artículo titulado «A propósito de la crítica de G. Fernández Farreres a la STC 247/2007», publicado en la Revista Española de Derecho Constitucional, núm. 83. 2008, págs. 149 y ss. 
Para ello, me referiré en primer lugar, brevemente, a los planteamientos jurídicos de las partes: a las «consideraciones generales» que encabezan el escrito de la demanda y constituyen el fundamento impugnatorio del recurso; y a las alegaciones de las otras partes personadas en el proceso, pues ellas reflejan las dispares concepciones de lo que es un Estatuto de Autonomía (I). A continuación analizaré los razonamientos jurídicos de la Sentencia, contenidos esencialmente en los FFJJ 3 a 6, y 57 y 58. Los primeros incluyen unas «consideraciones de principio», y un criterio interpretativo que después debe ser aplicado al enjuiciar los concretos preceptos impugnados (II). En tercer lugar, intentaré ver esta aplicación a los distintos Títulos del Estatuto (III). Y finalmente esbozaré alguna conclusión que, como casi siempre, debe ser provisional.

\section{LOS PLANTEAMIENTOS DE LAS PARTES}

En cuanto a los planteamientos de los demandantes, me parece útil mencionar que el Grupo parlamentario popular del Congreso ya interpuso en su día un recurso de amparo contra el Acuerdo de la Mesa del Congreso que calificó la propuesta de reforma del Estatuto de Cataluña de 1979 presentada por el Parlamento catalán como «propuesta de reforma del Estatuto», y la admitió a trámite. Los recurrentes alegaron entonces una vulneración del art. 23.2 CE aduciendo que al calificar la propuesta como reforma estatutaria, y no como reforma constitucional, la cual exige otra mayoría, la Mesa lesionó el derecho de participación de los Diputados de dicho grupo a intervenir en el procedimiento parlamentario. El contenido de dicha propuesta de reforma estatutaria presentaba notables diferencias respecto del texto finalmente aprobado por la Cortes y sometido a referéndum del cuerpo electoral de Cataluña. Pero resulta interesante comprobar que el argumento de los solicitantes de amparo fue que la propuesta «se extralimita consciente y deliberadamente del ámbito material constitucionalmente limitado de este tipo de iniciativa para convertirse en una reforma constitucional encubierta», denunciando las concretas vulneraciones constitucionales, entre otras, la conversión del poder legislativo estatutario en poder constituyente. El Tribunal declaró en el ATC 85/2006, de 15 de marzo, siguiendo la doctrina del ATC 135/2004, de 20 de abril (Plan Ibarrexe), que el recurso de amparo no podía servir para una impugnación abstracta de un proyecto de Estatuto de Autonomía, negando «la idoneidad objetiva para que un proyecto de norma pudiera de por sí vulnerar la Constitución, y la posibilidad de que este Tribunal interfiriese en el debate parlamentario en una especie de recurso previo» (FJ 2). Por ello, el Pleno inadmitió a trámite el recurso de amparo mediante el citado Auto, que contiene cinco Votos particulares premonitorios pues cuatro de sus firmantes formularon también Voto particular a la posterior STC 31/2010.

\section{a) El fundamento impugnatorio del recurso de inconstitucionalidad}

He mencionado el recurso de amparo del Grupo popular porque en él puede verse ya el núcleo de ese fundamento impugnatorio contenido en las «consideraciones generales» del posterior recurso de inconstitucionalidad que interpusieron frente al EAC 2006 (Antecedente 11), cuyo punto central es el ámbito material del Estatuto pues la demanda 
parte del concepto de «reserva estatutaria» para alegar una extralimitación de la misma, o de las «funciones propias de las normas estatutarias». Sobre este extremo los recurrentes defienden una interpretación restrictiva y relativa de la reserva estatutaria establecida en el art. 147.2 CE: los Estatutos se aprueban mediante leyes orgánicas y no pueden cumplir la función reservada a otras leyes orgánicas, ni a leyes ordinarias del Estado o leyes de rango inferior. Por ello se les podría aplicar la doctrina de las materias conexas, y no admitirían otro contenido adicional que no fuera el imprescindible para la regulación adecuada y sistemática del contenido material propio, por ejemplo, suplantando la función normativa de la Constitución.

Dado que la función constitucional del Estatuto no ha variado, pues no se ha reformado la Constitución de 1978 (CE), el EAC 2006 se extralimitaría al incluir materias que no ofrecen conexión alguna con la reserva estatutaria. Entre estas extralimitaciones se citan la regulación de derechos individuales, las relaciones de la Comunidad Autónoma con el Estado y las instituciones internacionales. Y también regulaciones que la CE atribuye a normas distintas del Estatuto: preceptos que incluyen mandatos al legislador estatal, o regulaciones sustitutorias de la legislación estatal a la que la CE se remite, además de normas meramente interpretativas desautorizadas por la STC 76/1983 (por ejemplo, las que pretenden blindar las competencias), que se enfrentarían a la jurisprudencia constitucional. El Estatuto, se concluye, llevaría a cabo una autoatribución de la competencia de la competencia, usurpando las funciones que la CE atribuye no solo al legislador estatutario sino al legislador del Estado y al Tribunal Constitucional.

Los principales argumentos de los recurrentes podrían sintetizarse en: a) la concepción del Estatuto como una ley orgánica con un ámbito material reservado por el art. 147.2 CE, sin poder entrar en el ámbito reservado a otras leyes orgánicas ni ordinarias, y a la que se podría aplicar la doctrina de las materias conexas; b) la función que la CE confiere al Estatuto impide que éste pueda realizar funciones como la de establecer mandatos al legislador estatal, o contener normas meramente interpretativas de la Constitución, lo cual está reservado al Tribunal Constitucional; c) el Estatuto no podría modificar la jurisprudencia constitucional, a pesar de formar parte del bloque de la constitucionalidad.

Como se verá, buena parte de los principales argumentos de los recurrentes son acogidos por la Sentencia, aunque de ellos el Tribunal no extrae todas las consecuencias al enjuiciar los concretos preceptos impugnados.

\section{b) Las alegaciones del Abogado del Estado}

El Abogado del Estado (Antecedente 12) delimita negativamente la función constitucional y el contenido de los Estatutos alegando que no es la propia de las Constituciones de los Estados miembro de un Estado federal, puesto que el Estado de la Autonomías no lo es en sentido genuino. El Estatuto está subordinado jerárquicamente a la Constitución y su contenido constitucional posible no se limita al contenido necesario del art. 147.2 CE pues la CE contiene numerosas remisiones a los Estatutos y además puede incluir otro contenido posible o lícito a partir de su condición de «norma institucional básica» de cada Comunidad Autónoma «dentro de los términos de la presente constitución», que lo hace norma de cabecera de cada ordenamiento autonómico, e instrument of government de la Comunidad. El problema del contenido lícito de un Estatuto queda li- 
gado a su especial rigidez, que solo alcanzaría a las materias del art. 147.2 CE, a las demás mencionadas en el texto constitucional o aquellas razonablemente ligadas a las anteriores. Y lo más importante: la consecuencia jurídica de las posibles extralimitaciones materiales no sería la nulidad del precepto estatutario sino el reconocimiento de la fuerza pasiva propia de la ley orgánica o de la ley ordinaria. Aplicando la técnica de las materias conexas se superarían las dificultades de la «no intercambiabilidad» del Estatuto con otras leyes orgánicas u ordinarias y se evitaría la declaración de nulidad buscando una interpretación conforme de los Estatutos.

Por otra parte, el Abogado del Estado niega que se haya invadido una reserva reglamentaria, que no existe en nuestro ordenamiento. También niega que el EAC 2006 haya usurpado funciones reservadas a otras normas en abstracto, pues ello solo se comprobará al examinar los concretos preceptos. Y finalmente considera gratuita la afirmación de que el nuevo Estatuto catalán se autoatribuye la competencia de la competencia pues estaríamos ante una reforma estatutaria que carece de virtualidad modificativa de la Constitución.

\section{c) Las alegaciones del Gobierno de la Generalitat}

El Gobierno de la Generalidad (Antecedente 13) alega que la demanda parte de un error puesto que la Constitución no ha definido el contenido de los Estatutos mediante una enumeración cerrada sino que abre un amplio espacio al legislador estatuyente a partir de la función que le atribuye de ser la «norma institucional básica» de la Comunidad Autónoma, subordinada a la Constitución, que se traduce en que es constitutiva de la Comunidad e incorpora aquellos elementos estructurales que sirven a esta función (instituciones, competencias, derechos y deberes, y aspectos del encaje en el Estado). Asimismo, sería también errónea la equiparación del Estatuto con las leyes orgánicas o de presupuestos, y por ello no podría trasladarse a aquél la doctrina de las materias conexas. Por otra parte, se niega que el Estatuto contenga normas meramente interpretativas de la Constitución, autoatribuyéndose la competencia de la competencia, y que su regulación se oponga a lo establecido por la jurisprudencia constitucional, pues sus criterios doctrinales no agotan definitivamente la determinación de todos los sentidos e interpretaciones que puedan darse a las normas constitucionales.

En relación con la función y contenido de los Estatutos, se alega que éstos se han considerado parte de la llamada «Constitución territorial» porque la CE remitió la concreta determinación de la organización territorial a posteriores decisiones de los poderes constituidos (desconstitucionalización parcial), lo cual se hizo a través de los Estatutos, que tienen por ello naturaleza «paraconstitucional»o «subconstitucional», denotando así su función de «complemento indispensable de la Constitución para la determinación de la forma de Estado». La representación del Gobierno de la Generalitat desarrolla los criterios definidores de los Estatutos como normas «específicas y diferenciadas» en los siguientes argumentos: a) representan un complemento indispensable de la Constitución para la determinación de la distribución territorial del poder e integran el «bloque de la constitucionalidad»; b) son instrumentos normativos de carácter paccionado pues su aprobación y reforma exigen la concurrencia de dos voluntades: la estatal y la autonómica; c) gozan de una especial fuerza pasiva debido a su excepcional rigidez en el procedimiento 
de reforma; d) una vez aprobados son inmunes a cualquier modificación realizada por ley orgánica u ordinaria, y por ello no pueden regular cualquier materia sino aquellas que sirven a su función constitucionalmente definida, si bien una vez promulgado todo su contenido queda afectado por la congelación.

Abunda la representación del Gobierno catalán en la función constitucional y contenido de los Estatutos señalando que concretan el ejercicio del derecho al autogobierno, determinan las instituciones, organización, competencias, relaciones con los ciudadanos, con el Estado y con otras instituciones, además de otros aspectos del autogobierno en base al principio dispositivo, y son norma de cabecera del ordenamiento autonómico. Atendiendo a esa función constitucional y al contenido propio del Estatuto como norma institucional básica, no se podría hablar de extralimitaciones por parte del EAC 2006, sino que aquéllos serían el criterio para determinar su contenido, distinguiendo entre el necesario e indisponible (art. 147.2 CE); el disponible en base a las habilitaciones constitucionales; y otros elementos que sirven a objetos directamente conexos con la función que la $\mathrm{CE}$ ha encomendado a la norma estatutaria (relaciones con los ciudadanos, con los poderes de otras CCAA, del Estado y de la UE).

Finalmente, el Gobierno de la Generalitat realiza unas consideraciones sobre la especial posición de los Estatutos como leyes orgánicas especiales, y su relación con otras leyes orgánicas. Se sostiene que el Estatuto prima sobre el resto de normas y puede sustituir a otras leyes orgánicas cuyo contenido propio goza de expresa reserva constitucional acudiendo a la distinción entre reserva relativa y reserva absoluta. No podría imputarse al EAC 2006 una invasión de reserva material a favor de otras leyes orgánicas, ya que la norma institucional básica puede y debe incorporar determinadas referencias a materias y órganos que hallan su regulación sustantiva en leyes orgánicas; y en tanto que ley orgánica estatal, el Estatuto podría complementar legítimamente al propio legislador orgánico, condicionando externamente en algunos aspectos concretos, como lo demostrarían las previsiones del Estatuto catalán de 1979 sobre determinadas materias reguladas por la LOPJ y la LOFCA.

\section{d) Las alegaciones del Parlamento de Cataluña}

Por último, el Parlamento de Cataluña (Antecedente 14) formula una alegación preliminar planteando la inadmisibilidad del recurso por el carácter preventivo de la impugnación, además de su carácter genérico y carente de fundamentación. Responde a la demanda afirmando que el EAC 2006 respeta la configuración constitucional del Estatuto, pues en su triple condición de norma creadora de la CA, norma institucional básica de la misma, y norma estatal, no puede limitar su contenido al del art. 147.2 CE. La regulación estatutaria no se definiría en relación con ninguna materia sino en función de la posición constitucional del ente creado por el Estatuto, el cual es además una ley estatal y por ello no puede decirse que imponga unilateralmente mandatos al legislador pues se aprueba por el propio Estado mediante ley orgánica. Pero es una norma pactada y una categoría singular en el sistema de fuentes, que se integra en el bloque de la constitucionalidad, sin otro parámetro de validez para enjuiciarlo que la propia Constitución. En cuanto a su relación con las demás leyes orgánicas, se argumenta en el mismo sentido que el Gobierno de la Generalitat. Respecto al contenido estatutario, se afirma que 
será válido si se corresponde con la función constitucional del Estatuto derivada de su carácter de norma institucional básica y no contraviene reservas constitucionales expresadas a favor de otra norma. Con base a este criterio, se defiende la regulación contenida en el EAC 2006 sobre derechos, materias reguladas por ley orgánica, relaciones con el Estado, y competencias, indicando que en este punto el Estatuto completa aquello que la CE ha dejado abierto, pudiendo llevar a cabo esa función delimitadora del alcance de las competencias. La representación del Parlamento catalán niega que se haya producido una autoatribución de la competencia de la competencia pues el EAC 2006 no impone una interpretación general y abstracta de la CE a las demás CCAA. Y niega asimismo que no se haya respetado la jurisprudencia constitucional, que no es inmodificable, y además ha sido dictada en aplicación de un bloque de la constitucionalidad que precisamente pretende modificar el nuevo Estatuto.

Como se ha dicho, los planteamientos de las partes que han quedado expuestos sintéticamente ponen de manifiesto concepciones dispares sobre la naturaleza normativa del Estatuto de Autonomía en nuestro ordenamiento constitucional. Y delimitan el ámbito de la controversia, acotando los puntos sobre los que el Tribunal debería pronunciarse para responder a las «consideraciones generales» formuladas por los recurrentes en su demanda. Queda claro que el núcleo de la cuestión debatida, como señala el mismo Tribunal, se circunscribe a la función y contenido de los Estatutos de Autonomía, su posición en el sistema de fuentes y su relación con la Constitución y las restantes normas del ordenamiento. Se trata de examinar ahora cuál ha sido la respuesta de la Sentencia a dicha cuestión, analizando los razonamientos jurídicos que ha empleado en su fundamentación.

\section{LOS RAZONAMIENTOS JURÍDICOS DE LA SENTENCIA}

La Sentencia rechaza las objeciones de procedibilidad denunciadas por el Parlamento catalán, quien sostuvo la inadmisibilidad del recurso, o al menos de esta parte, dado el carácter preventivo, genérico e infundado de las impugnaciones que contiene. El Tribunal responde que tales defectos deberán verificarse en cada una de las impugnaciones de los distintos preceptos, y coherentemente con ello, y con la argumentación que desarrollará, no emite en el fallo ningún pronunciamiento sobre los reproches de inconstitucionalidad genéricos que se vierten en las consideraciones generales.

La cuestión debatida se aborda en los FFJJ 3 a 6, y 57 a 60 de la Sentencia, aunque en realidad aquélla está presente a lo largo de toda la fundamentación. Los cuatro primeros fundamentos citados son lacónicos y taxativos, como toda la Sentencia, utilizan un tono marcadamente dogmático y sin apenas referencias a la jurisprudencia constitucional (solo en dos ocasiones se cita la STC 247/2007), con frecuentes afirmaciones apodícticas y algunas consideraciones de carácter preventivo. La respuesta a la cuestión se ofrece a través de una argumentación, eminentemente formalista, que sería la siguiente: el contenido posible de los Estatutos de Autonomía (FFJJ 4 y 5) viene determinado por su naturaleza (FJ 3) y su función constitucional (FJ 4), de los que se derivan unos límites cuantitativos y cualitativos a tal contenido (FJ 6). Esta argumentación solo contiene 
«consideraciones de principio» que han de concretarse al enjuiciarse cada precepto impugnado.

\section{a) La naturaleza y posición del Estatuto}

En cuanto a la naturaleza del el Estatuto de Autonomía, el Tribunal afirma que es una norma subordinada a la Constitución, «expresión de una autonomía fundamentada en la Constitución, y por ella garantizada». Ciertamente, la autonomía de las CCAA se funda en la CE (art. $137 \mathrm{CE}$ ), pero nada se dice del Estatuto como instrumento para el ejercicio del derecho a la autonomía de las nacionalidades y regiones garantizado por la Constitución (arts. 2 CE y 143.1 CE) ${ }^{8}$. Por otra parte, el Estatuto es expresión de una autonomía, en el sentido de un poder limitado (STC 4/1981, de 2 de febrero, FJ 3), cuya garantía no la ofrece tanto la Constitución, que puede ser reformada sin la participación de las CCAA, sino la rigidez de los mismos Estatutos, que no pueden ser reformados unilateralmente ni por el Estado ni por la $\mathrm{CA}^{9}$. Tampoco en este punto se hace referencia al carácter paccionado o complejo, a diferencia de lo que se declaraba en la STC 247/2007 (FJ 6), aunque éste es un aspecto controvertido de la naturaleza del Estatuto ${ }^{10}$.

La Sentencia rechaza que el cumplimiento de funciones «materialmente constitucionales» por parte de algunas normas jurídicas se traduzca en un «valor normativo añadido», pues aquella calificación tiene un alcance «puramente doctrinal o académico». Se aleja en este punto el Tribunal de la idea expresada en anteriores resoluciones, según la

8 Así se ha entendido generalmente por la doctrina y la jurisprudencia, tal como recogía el Informe sobre la reforma del Estatuto, elaborado por el Institut d'Estudis Autonòmics, Barcelona, 2003. En el mismo se afirma que el «Estatuto es, por tanto, el instrumento mediante el cual se produce el reconocimiento y garantía del derecho a la autonomía de las nacionalidades y regiones (art. 2 CE)», pág. 45.

9 Éste es el planteamiento de ARAGÓN REYES, M. cuando afirma que el «bloque constitucional» está integrado por normas (la Constitución y los Estatutos de Autonomía) que se caracterizan porque son indisponibles por el propio Estado de manera ordinaria, pues éste «solo puede alterarlas unilateralmente mediante la reforma constitucional» («La reforma de los Estatutos de Autonomía», recogido en Estudios de Derecho Constitucional, CEPC, 2009, págs. 810 y 811).

10 El Magistrado Javier Delgado Barrio formula en su Voto particular una original tesis según la cual el Estatuto de Autonomía «es fruto de la actuación de una competencia conjunta del Estado y de la Comunidad Autónoma (...) que la actúan sucesivamente (...) en un mismo procedimiento que tiene así un fondo paccionado, pues el Estatuto «supone una doble voluntad» - STC 59/1990, de 29 de marzo, FJ 5.» (Apartado 10)

11 En este sentido, para ArAgón ReYes, M., «en nuestro sistema de fuentes, la naturaleza jurídica de los Estatutos no esté determinada únicamente por la Constitución, sino también por los mismos Estatutos. Ya, solo este hecho, aproxima los Estatutos a la naturaleza de la Constitución y lo diferencia de la de la ley. Por ello, su especialísima proximidad con la Constitución no significa únicamente que formen parte del «bloque de constitucionalidad» por ser normas atributivas de competencia (...) sino también algo más profundo: que componen, conjuntamente con el texto de la misma Constitución, lo que podría llamarse «Constitución territorial» del Estado (en la que no se integran ningunas otras normas, ni siquiera las leyes del art. $150 \mathrm{CE}$ ) Así, en nuestro ordenamiento cabría distinguir un «bloque constitucional» de composición más restringida que el «bloque de constitucionalidad». (...). «los Estatutos de Autonomía, aunque no sean en nuestro ordenamiento (como sí lo son en Italia los de régimen especial), leyes constitucionales en sentido estricto, y esté sumamente clara aquí su subordinación a la Constitución, son una especie de leyes constitucionales secundarias (empleo términos de F. Rubio Llorente), es decir, de complemento necesario del texto constitucional (y no de simple desarrollo de éste), leyes, en fin, que han de gozar de aquello que caracteriza a la Constitución: su superior jerarquía sobre todas las leyes, incluidas las demás leyes orgánicas (así también lo entienden F. Rubio Llorente y E. García de Enterría, aunque no I. de Otto, que basa la distinción entre Estatutos y las demás leyes orgánicos en criterios com- 
cual los Estatutos «complementan» la Constitución (STC 247/2007, FJ 6), de lo cual se derivaban sus funciones constitucionales pero también su especial posición en el ordenamiento ${ }^{11}$.

Ahora se declara, en cambio, no solo que los Estatutos se integran en el Ordenamiento bajo la forma de ley orgánica, algo indiscutible a la vista del arts. 81 y $143.7 \mathrm{CE}$, lo cual significa que no se incorporan como otra categoría normativa, al modo por ejemplo de las leyes constitucionales. Se afirma que la posición de los Estatutos en el sistema de fuentes es «la característica de las leyes orgánicas ${ }^{12}$, esto es, la de normas legales que se relacionan con otras normas con arreglo a dos criterios de ordenación: el jerárquico y el competencial. En tanto que normas legales, el de jerarquía es el principio que ordena su relación con la Constitución en términos de subordinación absoluta». El principio de jerarquía también disciplina las relaciones del Estatuto de Autonomía con las normas de rango y fuerza inferior a la Ley, puesto que la «ley orgánica es, en definitiva, jerárquicamente $[\ldots]$ superior a las normas infralegales dictadas en el ámbito de su competencia propia». Por otra parte, «[e]n cuanto normas legales a las que queda reservada la regulación de ciertas materias, el principio de competencia es el que determina su relación con otras normas legales, cuya validez constitucional se hace depender de su respeto al ámbito reservado a la ley orgánica, de manera que el criterio competencial se erige en presupuesto para la actuación del principio de jerarquía, toda vez que de la inobservancia del primero resulta mediatamente una invalidez causada por la infracción de la norma superior común a la ley orgánica y a la norma legal ordinaria, es decir, por infracción de la Constitución». Finalmente, el principio de competencia disciplina también las relaciones entre los Estatutos de Autonomía y otras Leyes orgánicas, puesto que «[l]a reserva de ley orgánica no es siempre, sin embargo, la reserva a favor de un género, sino que en ocasiones se concreta en una de sus especies. Tal sucede, por ejemplo, con la

petenciales, o mejor dicho, de distribución de materias)», («La reforma de los Estatutos de Autonomía», cit., págs. 809 a 811). El Dictamen 269 del Consejo Consultivo de la Generalitat, en relación con la propuesta de reforma del Estatuto de Cataluña, declaró que «los Estatutos completan la Constitución y han podido ser calificados como instrumentos de naturaleza «paraconstitucional»o, con mayor precisión, «subconstitucional», entendiendo con este expresión no sólo su carácter subordinado a la Constitución, sino también su función de complemento indispensable de la Constitución para la determinación de la estructura territorial del Estado.» (CONSEJO CONSULTIVO DE LA GENERALIDAD DE CATALUÑA, Dictámenes 2005, pág. 168).

12 Ésta es la tesis defendida por Aguado Renedo, C., El Estatuto de Autonomía y su posición en el ordenamiento jurídico, CEC, Madrid, 1996; y reafirmada posteriormente, a la vista de la reforma estatutaria catalana, en «De nuevo sobre la naturaleza jurídica del Estatuto de Autonomía, con motivo de los procesos de reforma», Asamblea. Revista parlamentaria de la Asamblea de Madrid, num. 17, 2007. Las distintas posiciones doctrinales sobre esta cuestión se exponen en CASTELlà ANDReu, J. M., La función constitucional del Estatuto de Autonomía de Cataluña, IEA, Barcelona, 2004, págs. 181 a 200. La aprobación de las reformas estatutarias mediante ley orgánica, en cambio, mereció una reflexión crítica del Consejo de Estado en su «Informe sobre modificaciones de la Constitución Española» (Febrero, 2006), donde declaró: «Esta forma [de ley orgánica] que el texto actual [de la Constitución] impone ha dado lugar a una confusión perturbadora, de la que a veces se ha intentado sacar provecho. Pese a estar aprobados por ley orgánica, los Estatutos no son leyes orgánicas, sino una fuente normativa distinta. Ni las leyes orgánicas posteriores pueden modificar los Estatutos, o desconocerlos, ni los Estatutos pueden ignorar o modificar leyes orgánicas existentes». A la vista de lo anterior, el Informe proponía que los Estatutos se aprobaran por las Cortes Generales mediante el trámite previsto en el artículo 74 CE. (Ver Rubio Llorente, F- Álvarez Junco, J. (eds.), El informe del Consejo de Estado sobre la reforma constitucional. Texto del informe y debates académicos, Consejo de Estado-CEPC, Madrid, 2006, pág. 174) 
reguladora del Poder Judicial (art. 122.1 CE) y, justamente, con cada una de las leyes orgánicas que aprueban los distintos Estatutos de Autonomía. La ley orgánica no es en estos casos una forma fungible, sino que, en relación con las concretas materias reservadas a una ley orgánica singular, las restantes leyes orgánicas se relacionan también de acuerdo con el principio de la distribución competencial. Así las cosas, la posición relativa de los Estatutos respecto de otras leyes orgánicas es cuestión que depende del contenido constitucionalmente necesario y, en su caso, eventualmente posible de los primeros» [la cursiva es nuestra]. Con las anteriores afirmaciones de carácter dogmático se inicia un razonamiento circular: la naturaleza del Estatuto y su posición respecto de otras leyes orgánicas depende de su contenido constitucionalmente posible, pero éste a su vez viene determinado por la naturaleza y función constitucional del Estatuto.

En este punto es importante destacar que, para el Tribunal, la forma jurídica a través de la cual se aprueba y modifica el Estatuto de Autonomía, es decir la de ley orgánica, determina en exclusiva su posición dentro del sistema de fuentes, excluyendo que pueda ocupar una posición singular derivada de consideraciones de orden funcional. No se plantea pues si la función constitucional del Estatuto de Autonomía condiciona o afecta en alguna medida a sus relaciones con otras Leyes estatales y, en particular, con otras Leyes Orgánicas y con la legislación básica del Estado. Tampoco se pronuncia expresamente sobre si esas relaciones se ven condicionadas de algún modo por el hecho de que el procedimiento de aprobación y reforma configure al Estatuto de Autonomía como una norma pactada dotada de una legitimidad democrática reforzada.

La STC 31/2010 no reproduce, ni aplica posteriormente, la doctrina establecida en la STC 247/2007 a propósito de las relaciones entre los Estatutos de Autonomía y las Leyes Orgánicas. En esa resolución, después de constatar que los Estatutos de Autonomía son aprobados mediante una Ley Orgánica, de tal manera que las relaciones con otras Leyes Orgánicas se regulan «por la propia Constitución, según criterios de competencia material, de modo que el parámetro de relación entre unas y otras es, exclusivamente, la Norma constitucional», se concluía lo siguiente: «[d]e ahí que la reserva material que, en términos específicos para cada caso, realiza la Constitución a favor de determinadas leyes orgánicas, suponga que cada una de dichas leyes pueda llevar a cabo una delimitación de su propio ámbito (STC 154/2005, de 9 de junio, FFJJ 4 y 5, con referencia a otras), circunscribiendo la eficacia de las normas estatutarias de acuerdo con dicha delimitación. Pues bien, en caso de colisión, será competencia de este Tribunal la apreciación del alcance de la correspondiente reserva y sus efectos sobre la validez o eficacia de la normativa estatutaria» (FJ 6). Se ha observado acertadamente ${ }^{13}$ que la STC 31/2010 no rechaza expresamente este planteamiento, pero el silencio que guarda al respecto y el hecho de que no se recurra al mismo a la hora de enjuiciar las concretas disposiciones impugnadas, acaso permita deducir, de un parte, que en esta resolución el Tribunal no contempla la posibilidad de que se produzcan, siquiera sea prima facie, solapamientos entre los ámbitos materiales constitucionalmente reservados a las Leyes Orgánicas específicas expresamente previstas en la Constitución (salvo, quizás, algún supuesto excepcional como el

13 Arroyo JimÉnez, L.-Nieto Garrido, E.: «Las resoluciones del Tribunal Constitucional en los procesos de control de constitucionalidad de la ley», Crónica de jurisprudencia presentada en las XVI Jornadas de Letrados del Tribunal Constitucional, Murcia, 21-23 de octubre 2010. (en curso de publicación) 
que se deriva de los arts. 3.2 y 122 CE en relación con las consecuencias propias de la cooficialidad en el ámbito reservado a la Ley Orgánica del Poder Judicial); y de otra, que, en caso de que se produjera un conflicto entre disposiciones contenidas en un Estatuto de Autonomía y en otra Ley Orgánica, el conflicto entre tales normas sólo podría resolverse en el plano relativo a su validez, puesto que «de la inobservancia del [principio de competencia] resulta mediatamente una invalidez causada [...] por infracción de la Constitución» (FJ 3). En realidad, la Sentencia opta por una solución, que no explicita, consistente en el vaciamiento del contenido propio de algunas disposiciones impugnadas, de forma que el resultado de la ineficacia de la norma se obtiene por una vía interpretativa, es decir, sin declaración de inconstitucionalidad (Voto particular del Magistrado Delgado Barrio, Apartado 3 D).

Retomemos el razonamiento del Tribunal, según el cual el contenido posible de los Estatutos de Autonomía viene determinado por su naturaleza y su función constitucional. Ya hemos reseñado lo que declara la Sentencia sobre la naturaleza y posición del Estatuto, y también lo que silencia: el Estatuto es una ley orgánica y esa es su posición en el ordenamiento, que no se ve singularizada por la función «materialmente constitucional» que desempeña, la cual no le confiere ningún «valor normativo añadido», ni por el hecho de que el procedimiento de aprobación y reforma lo configure como una norma pactada y dotada de una legitimidad democrática reforzada, pues la Sentencia guarda silencio sobre la circunstancia de que la norma enjuiciada, excepcionalmente, haya sido aprobada en referéndum por el cuerpo electoral de Cataluña. Veamos ahora lo que se declara sobre la función constitucional del Estatuto.

\section{b) La función constitucional del Estatuto}

La argumentación en este punto se inicia con el recordatorio, excepcional, de la STC 247/2007, según la cual los Estatutos, además del contenido «constitucionalmente obligado (art. 147.2 CE)», y del «constitucionalmente posible en virtud de previsiones constitucionales expresas» (arts. 3.2, 4.2, 69.5 CE), podrían tener un «contenido adicional» derivado de «la función y cualidad del Estatuto», que sería «complemento adecuado por su conexión con las aludidas previsiones constitucionales, adecuación que ha de entenderse referida a la función que en sentido estricto [la Constitución] le encomienda a los Estatutos, en cuanto norma institucional básica que ha de llevar a cabo la regulación funcional, institucional y competencial de la Comunidad Autónoma». Ese contenido adicional del Estatuto derivaría de su naturaleza y «función constitucional», no en el sentido de realizar una función «materialmente» constitucional sino de venir conferida o encomendada por la Constitución.

La primera función constitucional del Estatuto sería «la diversificación del Ordenamiento mediante la creación de sistemas normativos autónomos», respecto de los cuales aquél es norma institucional básica (art. 147.1 CE). En esa primera función no se cita pues su carácter de norma fundacional singular de cada Comunidad Autónoma; ni su función constitucional general en tanto que normas llamadas por la Constitución a completar la organización territorial del Estado, la cual se concreta a través de la llamada «Constitución terri-

14 Sobre la naturaleza del mismo, puede verse Fossas EsPaDALER, E., El principio dispositivo en el Estado Autonómico, Marcial Pons, IVAP, 2007, págs. 81 y ss. 
torial»; ni de su vinculación con el principio dispositivo, que es un principio constitucional inspirador de aquella organización y la singularidad más destacada de nuestra Carta Magna ${ }^{14}$.

La segunda función constitucional radicaría en ser «norma de garantía de la indemnidad del sistema autónomo, toda vez que el Estatuto es condición de la constitucionalidad de todas las normas del Ordenamiento en su conjunto, también de las que comparten su forma y rango». Con ello parece referirse el Tribunal al «bloque de la constitucionalidad», expresión que no utiliza, si bien se precisa que la Constitución «es la única norma que en puridad determina la constitucionalidad de cualquier norma». En realidad, la Sentencia no afirma que el Estatuto forme parte del «bloque de la constitucionalidad», y no hace ninguna referencia a las alegaciones de las partes según las cuales la modificación del Estatuto obligaría a revisar la jurisprudencia constitucional al haberse modificado aquél. Al contrario, y como se verá, se insiste en la necesidad de que los nuevos contenidos estatutarios respeten la Constitución y la interpretación que de ella ha hecho el Tribunal. De la Sentencia se desprende que la situación del Estatuto dentro del bloque de la constitucionalidad no le da ninguna fuerza para imponer nuevas interpretaciones del texto constitucional con la finalidad de incrementar el autogobierno ${ }^{15}$.

La tercera función que la Constitución encomienda al Estatuto sería la de «atribución competencial, que define, por un lado, un ámbito privativo de formación y de ejercicio del poder público por parte de la Comunidad Autónoma (...), y contribuye a perfilar, por otro, el ámbito de formación y poder del propio Estado», pero ello «no hace del Estatuto (...) una norma atributiva de competencias del Estado». Esta función se concretará posteriormente, especialmente en los FFJJ 57 a 60, al analizar las normas estatutarias definitorias de los tipos competenciales (arts. 110, 111, 112 EAC). Lo declarado en este punto contrasta con la afirmación contenida en la STC 247/2007, según la cual los Estatutos «desempeñan un papel de gran relevancia para la configuración del sistema de reparto de competencias entre el Estado y las Comunidades Autónomas» (FJ 7), de acuerdo con el art. 147.2 d). El Tribunal declara ahora que el contenido posible del Estatuto «excluye como cometido de este tipo de norma la definición de categorías constitucionales» (tales como competencia, legislar, ejecutar, juzgar, derechos $)^{16}$ «constitutivas del lenguaje en el que ha de entenderse la voluntad constituyente», tarea que corresponde al Tribunal Constitucional en su condición de intérprete supremo de la Constitución, "único competente para la definición auténtica —e indiscutible — de las categorías y principios constitucionales» [la cursiva es nuestra] pues «ninguna norma infraconstitucional puede hacer las veces de poder constituyente prorrogado o sobrevenido» (FJ 57). Ni siquiera en el caso de que tales normas reprodujeran la jurisprudencia constitucional, pues ello supondría «hacerse con la función más propia del Tribunal Constitucional» (FJ 58). La Sentencia admite la indefinición del texto constitucional en la determinación y alcance de las competencias, y acepta que los Estatutos, al integrar el contenido funcional de las competencias asumidas por la Comunidad Autónoma, puedan

15 Tonos Mas, J., art cit. pág. 24

16 El Tribunal excluye la posibilidad de que el Estatuto lleve a cabo tales definiciones, y ello parece anunciarse como ratio decidendi al inicio del FJ 57. Sin embargo, en el FJ 58 declara que los arts. 110, 111 y 112 EAC «no pretenden disciplinar una cuestión ajena a la disponibilidad del legislador constituido como es la definición misma de qué sean las potestades legislativa, reglamentaria y ejecutiva comprendidas en las competencias de las que puede ser titular la Comunidad Autónoma de Cataluña». 
«relacionar sin definir, esto es, sin otro ánimo que el descriptivo de una realidad normativa que le es en sí misma indisponible». De ahí que las previsiones estatutarias citadas se consideren «constitucionalmente aceptables en la medida que, con la referida voluntad de descripción y de sistema, se acomoden a la construcción normativa y dogmática que cabe deducir de nuestra jurisprudencia en cada momento histórico, es decir, sin que su formalización como expresión de la voluntad del legislador orgánico estatutario suponga un cambio en su cualidad normativa, que será siempre, de no mediar una reforma expresa de la Constitución, la propia del ejercicio de nuestra jurisdicción» (FJ 58).

En el anterior razonamiento el Tribunal señala las funciones que la Constitución confiere a los Estatutos, y a sensu contrario las que no se deducirían de aquélla: no habla de la función constitutiva como «norma fundacional de la correspondiente Comunidad Autónoma» (STC 247/2007, FJ 5), ni de su función como parte de la llamada «Constitución territorial» del Estado; no hace ninguna referencia a la integración del Estatuto en el «bloque de la constitucionalidad», como parámetro de apreciación de la constitucionalidad de las leyes, tanto estatales como autonómicas. Y finalmente, aunque sea lo más importante, no reserva prácticamente ningún papel al Estatuto en la función de configurar el sistema de reparto de competencias entre el Estado y las Comunidades Autónomas, auto atribuyéndose el Tribunal esta función a partir directamente y exclusivamente de la Constitución ${ }^{17}$. Queda pues el último paso del razonamiento, a saber, delimitar el contenido posible de los Estatutos de Autonomía a la luz de lo declarado sobre su naturaleza y su función constitucional.

\section{c) El contenido posible de los Estatutos}

De la naturaleza y funciones atribuidas por la Constitución a los Estatutos se derivaría su «contenido posible» y sus límites. Ese contenido posible estaría formado en primer lugar por el contenido «constitucionalmente explícito», integrado a su vez por el contenido «obligado» (art. 147.2 CE) y por el contenido previsto en disposiciones constitucionales expresas (arts. 3.2 y $4.2 \mathrm{CE}$ ). Y en segundo lugar por «un contenido implícito por inherente a la condición del Estatuto como norma institucional básica (art. 147.1 CE) con cuanto ello implica en términos de autogobierno, de autoorganización y de identidad». El Tribunal admite pues un contenido material amplio de la norma estatutaria, dada la «apertura y flexibilidad del modelo territorial», pero sometido a unos límites.

Los límites serían de orden cuantitativo, «toda vez que la especial rigidez del Estatuto de Autonomía supone una petrificación de su contenido que puede llegar a no compadecerse con un efectivo derecho de participación política en el ejercicio de los poderes constituidos». Sin embargo, se admite que los reparos que pudieran oponerse en este sentido «no dejan de ser en muchas ocasiones otra cosa que una objeción de simple oportunidad, sin relevancia, por tanto, como juicio de constitucionalidad strictu sensu; y de otro, que los Estatutos de Autonomía también son obra del legislador democrático».

En cuanto a los límites cualitativos, son aquellos que definen la diferencia entre la Constitución y los Estatutos, como los que «delimitan los ámbitos inconfundibles del poder constituyente, por un lado, y de los poderes constituidos, por el otro», que resultan

17 Albertí Rovira, E.: «El Estado de la Autonomías después de la STC sobre el Estatuto de Cataluña», El Cronista del Estado Social y Democrático de Derecho, núm. 15, 2010, pág. 96 
inaccesibles a cualquier legislador y «solo al alcance de la función interpretativa de este Tribunal Constitucional (STC 76/1983, de 5 de agosto, passim)». De todas formas, éstas son «consideraciones de principio» realizadas en el FJ 6, en el que se advierte sin embargo que habrán de concretarse «al enjuiciar cada uno de los preceptos impugnados, determinando entonces la verdadera medida del grado de colaboración constitucionalmente necesaria $y$ admisible por parte del legislador estatuyente en la tarea de la interpretación constitucional característica de una sociedad democrática» [la cursiva es nuestra]. De ello se deduce que la doctrina del Tribunal sobre la naturaleza, función y contenido del Estatuto no queda fijada únicamente en los FFJJ 3 a 6 sino en el conjunto de la Sentencia, pues es en el enjuiciamiento de los numerosos preceptos impugnados donde se proyecta la concepción de la norma estatutaria que en esta resolución sostiene el Tribunal.

Las consideraciones del FJ 6, y las afirmaciones contenidas en los FFJJ 57 y 58 quedan lejos de las que el mismo Tribunal realizó en los FFJJ 7 a 10 de la STC 247/2007, donde hizo una valoración muy diferente de la función interpretativa de la Constitución que puede legítimamente realizar el Estatuto de Autonomía, con los límites que afectan a todo legislador, derivados de la STC 76/1983, puntualizando sin embargo que «la Constitución no impide al legislador ordinario su interpretación, pues ningún precepto de aquélla así lo declara ni este Tribunal ha admitido la existencia de reservas implícitas a favor del constituyente» (FJ 8). En efecto, en aquella resolución se recogió una consolidad doctrina que, precisando la STC 76/1983, declaraba la legitimidad de la interpretación constitucional llevada a cabo por el legislador ordinario, estatal o autonómico, así como los límites de tal interpretación: que no se trate de una interpretación «genérica y abstracta» del sistema de reparto de competencias; y que sus normas se dirijan «a su ámbito competencial». Y lo que es más importante: extendía también al Estatuto de $\mathrm{Au}$ tonomía, en tanto que norma estatal y norma institucional básica de la CA, esa capacidad de interpretación de la Constitución, con los límites señalados, a los que se añadía un tercero: que la regulación normativa estatutaria, al realizar su función atributiva de competencias «no puede en ningún caso quebrar el marco del art. 149.1 CE» (FJ 10). Pues bien, la STC 31/2010 omite esa doctrina y niega al legislador estatutario lo que, hasta hoy, aquélla había permitido al legislador ordinario, estatal o autonómico ${ }^{18}$.

$\mathrm{Al}$ respecto, se ha señalado ${ }^{19}$ que los pronunciamientos del Tribunal acerca de los límites cualitativos a los que está sometido el contenido adicional del Estatuto de Autonomía suponen subrayar la supremacía de la interpretación de las categorías y conceptos constitucionales realizada por el Tribunal Constitucional frente a la que incumbe al le-

18 En este punto la Sentencia parece seguir la tesis según la cual el nuevo Estatuto catalán pretendería realizar una función de «LOAPA invertida», formulada por ORTEGA, L., La redefinición de los estatutos de autonomía de la distribución territorial del poder contemplado en la Constitución, Ministerio de Administraciones Públicas, Madrid, 2005. Esta tesis fue refutada por el trabajo de Viver Pi-SunYer, C.: «En defensa de los Estatutos de Autonomía como normas jurídicas delimitadoras de competencias. Contribución a una polémica jurídico-constitucional», en Ruiz Rico, G. (coord.), Las reformas de los Estatutos de Autonomía. Actas del II Congreso Nacional de la Asociación de Constitucionalistas de España, Tirant Lo Blanc, Valencia, 2006, pág. 67. Este trabajo, a su vez, fue contestado por otro de Ortega, L.: «Legislación básica y Estatutos de Autonomía», en OrTegA, L.- Solazábal Echavarría, J. J.-Arbós Marín, X., Legislación básica y Estatuto de Autonomía, CEPC, Madrid, 2006.

19 Arroyo Jimenez, L.-Nieto Garrido, E. Ver nota 13. 
gislador estatutario, por más que ésta responda a una «colaboración constitucionalmente necesaria y admisible», y con ello, el rechazo a una posible comprensión de las consecuencias de la denominada «desconstitucionalización» del modelo territorial del Estado, y, en particular, de aquella en virtud de la cual el contenido del Estatuto se impondría al Tribunal como norma constitucional secundaria como consecuencia de su función de complemento de la Constitución y la consiguiente inclusión en el bloque de constitucionalidad ${ }^{20}$. La doctrina académica ha debatido acerca de si esta propuesta fue asumida en sus propios términos por el Tribunal en su STC 247/2007, pero parece fuera de toda duda que la STC 31/2010 ha rechazado con contundencia esa posibilidad ${ }^{21}$.

Además del reconocimiento de la supremacía de la interpretación de la Constitución realizada por el Tribunal Constitucional, el rechazo de la mencionada tesis implica también que no es al legislador estatutario, sino al legislador estatal no estatutario a quien corresponde la delimitación unilateral del alcance de sus propias competencias, especialmente de las básicas y de los títulos competenciales de carácter horizontal, sin que al Estatuto de Autonomía se le reconozca la posibilidad de colaborar en esa tarea ni de «dirigir mandatos o requerimientos al legislador estatal $»^{22}$.

\section{EL MODO DE APLICACIÓN DE LAS «CONSIDERACIONES DE PRINCIPIO»AL CONTENIDO DEL EAC 2006}

Como se ha visto, la respuesta del Tribunal a la cuestión clave que suscita el recurso de inconstitucionalidad contra el nuevo Estatuto catalán es que el contenido posible de los Estatutos puede ser amplio, pues además del contenido explícito (el constitucionalmente obligado y el constitucionalmente posible en virtud de previsiones constitucionales expresas), cabe un contenido implícito por inherente a la condición del Estatuto como norma institucional básica (contenido adicional derivado de «la función y cualidad del Estatuto»). Pero ese contenido adicional está sometido a unos límites cuantitativos y cualitativos derivados de la naturaleza y funciones atribuidas por la Constitución a los mismos, es decir, de su valor jurídico tal como se interpreta en los pronunciamientos contenidos en esas «consideraciones de principio» (FJ 6), analizadas en el apartado anterior, que deben luego ser aplicadas al enjuiciar cada uno de los preceptos impugnados, los cuales abarcan todos los Títulos del EAC 2006.

La aplicación de los anteriores razonamientos jurídicos a las distintas partes del EAC 2006 se lleva a cabo mediante una operación que consiste en mantener la práctica totalidad de los preceptos estatutarios sin declarar su inconstitucionalidad (y, por consiguiente, conservando casi íntegramente el contenido material del nuevo texto estatutario catalán), pero utilizando de manera heterodoxa la técnica de la interpretación conforme. Esta singular técnica adopta varias formas: realizando interpretaciones de

20 Tesis sostenida por Viver Pi-Sunyer, C., art. cit., pág. 67

21 Así lo entiende Fernández Farreres, G.: «Las competencias de Cataluña tras la Sentencia del Tribunal Constitucional sobre el Estatut», El Cronista del Estado Social y Democrático de Derecho, núm. 15, 2010, págs. 42 y ss.

22 Tornos MAs, J., art. cit., pág. 24 
conformidad que no se llevan al Fallo, manipulando los enunciados legales mediante la creación de una nueva norma (en alguna ocasión contraria al sentido literal del precepto estatutario enjuiciado), o devaluando la fuerza normativa de muchos preceptos, de tal manera que numerosas materias reguladas por primera vez en un Estatuto pierden buena parte de su valor prescriptivo ${ }^{23}$.

El Tribunal admite pues que determinadas materias pueden formar parte del Estatuto, pero a cambio de restarles su valor normativo o de interpretar su alcance en un sentido distinto del que se deriva del texto estatutario. El Estatuto de Autonomía es la norma institucional básica de la Comunidad Autónoma aunque es solo una ley orgánica subordinada a la Constitución; puede tener un amplio contenido, pero al ser fruto de un poder constituido (STC 76/1983) y con un alcance territorial limitado, se impone la primacía de los conceptos constitucionales y de la doctrina del propio Tribunal sobre los preceptos estatutarios, los cuales solo son constitucionales interpretados en el sentido que fija la fundamentación.

A lo largo de la Sentencia pueden verse numeroso ejemplos de la aplicación de esta forma de proceder a las distintas partes del Estatuto, de las que a continuación solo se relacionan algunas.

a) El Estatuto es la norma competente para atribuir al catalán la condición de lengua oficial en Cataluña y definir su estatuto jurídico (FJ 21), pero el régimen jurídico de las lenguas oficiales se desprende directamente de la Constitución, la cual impone un equilibrio inexcusable entre dos lenguas igualmente oficiales, razón por la cual la declaración de que el catalán será lengua de uso «preferente» en las Administraciones Públicas, consecuencia de su declaración de «lengua propia», no admite una interpretación conforme a la Constitución (FJ 14). Asimismo, el deber de conocimiento del catalán se declara que no es inconstitucional, y así se dispone en el fallo, si se interpreta que no es equivalente al deber constitucional de conocimiento del castellano si no que se trata de un deber «individualizado y exigible» solo en algunos ámbitos como la educación o la función pública, pero «no es jurídicamente exigible con carácter generalizado». Y ello porque el deber de conocimiento de una las lenguas oficiales distintas del castellano no viene impuesto por la Constitución y no es inherente a la cooficialidad.

Aún en el ámbito de la lengua, la exigencia estatutaria de acreditación de conocimiento de las dos lenguas oficiales a Jueces, Magistrados, Fiscales, Notarios, Registradores, personal al servicio de la Administración de Justicia y de la Administración del Estado, se acepta solo si se interpreta que se trata de una «exigencia para cuya articulación el Estatuto remite "a la forma establecida en las leyes"», que serán las estatales en virtud de las correspondientes reservas establecidas en la Constitución. Asimismo es objeto de interpretación conforme, que se lleva al fallo, el precepto que consagra el derecho a relacionarse por escrito en catalán con los órganos constitucionales y jurisdiccionales de ám-

23 La singular forma de utilizar la técnica de la interpretación conforme en la STC 31/2010 ha sido uno de los principales motivos de discrepancia de los Votos particulares, y objeto de crítica generalizada por parte de la doctrina. Ver las contribuciones incluidas en Revista Catalana de Dret Públic. Número especial sobre la STC 31/2010. Septiembre 2010. (http://www.rcdp.cat); y las incluidas en El Cronista del Estado Social y Democrático de Derecho, núm. 15, 2010, ya citado. Asimismo, Blanco VAldÉs, R. L.: «El Estatuto catalán y la Sentencia de nunca acabar», Claves de Razón Práctica, núm. 205, 2010, págs. 4 y ss.; DE CARreras, F.: «¿Es constitucional el Estatuto de Cataluña?, Claves de Razón Práctica, núm. 206, 2010, págs. 10 y ss. 
bito estatal (art. 33.5 EAC), al entender que «la existencia o no de eficacia jurídica de los escritos presentados en catalán a dichos órganos, y en su caso, el grado de ésta ha de ser establecidos con entera libertad, dentro de los límites constitucionales (art. 3.1 CE), por el legislador estatal competente.» (FJ 21).

b) El Estatuto puede incluir un Título sobre los derechos estatutarios, pero «ni el Estatuto ha creado derechos fundamentales distintos de los proclamados en la Constitución o en contradicción con ellos, ni ha podido afectar al régimen de tales derechos». La condición del Estatuto como norma institucional básica, y su vigencia territorial limitada, le impediría realizar la «función de desarrollo» de los derechos fundamentales (art. $81 \mathrm{CE}$ ), materia que se reserva «al género de la ley mediante la cual se aprueba». Es más, el Estatuto, en tanto que ley orgánica, no solo no podría «declarar o desarrollar derechos fundamentales» sino «siquiera regular el ejercicio de tales derechos», algo que sí «podrá hacerlo, en su caso, el legislador autonómico» (FJ 18).

c) No podría formularse ninguna objeción a que el Estatuto, en tanto que norma institucional básica, contenga «las líneas fundamentales» del régimen local en el ámbito territorial de la Comunidad Autónoma y «difícilmente puede afirmarse el fin del carácter bifronte del régimen local», pues el ejercicio de las competencias autonómicas en esta materia ha de ajustarse «a la competencia que sobre las bases de la misma corresponde al Estado ex 149.1.18 CE» (FJ 36, que debe leerse conjuntamente con el FJ 100 , que trata de las competencias sobre «régimen local»). Se admite pues que el Estatuto enumere una serie de materias sobre las que los gobiernos locales han de tener en todo caso competencias propias, pero deben ser «materias de competencia autonómica», y «en modo alguno sustituye ni desplaza, sino que, en su caso, se superpone, a los principios o bases que dicte el Estado sobre las competencias locales en el ejercicio de la competencia constitucionalmente reservada por el art. 149.1.18 CE», aunque éste no se mencione expresamente en precepto estatutario (FJ 37). La nueva organización del gobierno local de Cataluña (art. 83.1 EAC), que se basa en el municipio y la nueva institución de la «veguería» (art. 90 EAC), sin mención de la provincia, no se reputa inconstitucional si se interpreta que «no puede suponer la supresión de las provincias en Cataluña ni la de sus funciones constitucionales» (FJ 40).

d) El Estatuto puede contener previsiones sobre la Administración de Justicia, pero no sobre el Poder Judicial ya que el Estado Autonómico, a diferencia del federal, no presenta una diversificación de la función jurisdiccional, que pertenece solo al Estado central, es decir, que «la estructura territorial del Estado es indiferente, por principio, para el Judicial como Poder del Estado», lo cual es compatible con el reconocimiento a las CCAA de determinadas competencias en el ámbito de «administración de la Administración de Justicia» (FJ 42). De acuerdo con esta premisa, el Estatuto puede definir al TSJ de Cataluña como el «órgano jurisdiccional en que culmina la organización judicial en Cataluña» y fija sus competencias «en los términos establecidos por la ley orgánica correspondiente», pues entiende que el precepto estatutario se limita a reproducir la previsión del art. 152.1 CE (FJ 43). En cambio, el art. 95.2 EAC, que hace del TSJ la «última instancia jurisdiccional de todos lo procesos iniciados en Cataluña (...) sin perjuicio de la competencia reservada al Tribunal Supremo para la interpretación de doctrina», se declara que no es contrario a la Constitución si se interpreta ese último inciso en el sentido de que «ni el Estatuto puede contraer la competencia de ese Tribunal [Supremo] al 
conocimiento de un determinado recurso judicial, ni definir (...) las competencias jurisdiccionales del Tribunal Supremo» (FJ 44). En el ámbito de la Justicia, el Tribunal declara que al crear el Consejo de Justicia de Cataluña (art. 97 EAC), como «órgano de gobierno del poder judicial en Cataluña», el Estatuto «incurre en un evidente exceso» pues «ningún órgano, salvo el Consejo General del Poder Judicial, puede ejercer la función de gobierno de los órganos jurisdiccionales integrados en el Poder Judicial, exclusivo del Estado, ni otra ley que no sea la Orgánica del Poder Judicial puede determinar la estructura y funciones de aquel», por lo que declara la inconstitucionalidad del precepto, si bien solo en la medida en que califica al Consejo de Justicia de Cataluña como «órgano de gobierno del poder judicial» que «actúa de forma desconcentrada del Consejo General del Poder Judicial». De lo anterior deduce el Tribunal, sorprendentemente, que no plantearía ningún reparo constitucional la existencia del un Consejo de Justicia de Cataluña que ejerciera competencias asumidas en relación con la «administración de la Administración de Justicia», pero no buena parte de las relacionadas en el art. 98.2 EAC, cuya inconstitucionalidad y nulidad se declaran en el FJ 48.

e) En cuanto a la función de distribución competencial, una de las principales que la Constitución encomienda al Estatuto, me remito al apartado anterior, en el que ha quedado expuesto el principal pronunciamiento de la Sentencia, a saber, que el Estatuto puede «describir» los ámbitos funcionales y materiales de las competencias, pero el alcance competencial de la Generalidad es el que establece la Constitución y la interpretación que de ella haga el Tribunal Constitucional, que se declara único competente para la definición auténtica e indiscutible de las categorías y principios constitucionales pues «ninguna norma infraconstitucional puede hacer las veces de poder constituyente prorrogado» (FJ 57). En este punto clave, la Sentencia llega a atribuir al Tribunal el carácter no ya de poder constituyente prorrogado sino prácticamente de poder constituyente, sin más. Así, por ejemplo, la definición de las categorías constitucionales (como son los tipos de competencias y su contenido) son «constitutivas del lenguaje en el que ha de entenderse la voluntad constituyente, $[\mathrm{y}]$ no pueden tener otra sede que la Constitución formal, ni más sentido que el prescrito por su intérprete supremo (art. 1.1 LOTC)» (FJ 57). Asimismo, señalar si las bases son «principios» o formación mínima» no es asunto a dilucidar en un Estatuto «sino solo en la Constitución, vale decir: en la doctrina que este Tribunal que la interpreta» (FJ 60).

La Sentencia acepta que «no pocas de las competencias estatales vienen mediatamente determinadas por los Estatutos, si bien únicamente en el si y en el quantum» (FJ 5), pero rechaza la posibilidad de que el Estatuto de Autonomía delimite de algún modo las competencias del Estado. Abandona así, aún sin citarla, la construcción de la STC 247/2007 sobre la relación entre el Estatuto y las competencias estatales del art. 149.1 CE. En aquella resolución se afirmaba que el «Estatuto de Autonomía, en cuanto que es norma estatal, puede realizar su función atributiva de competencias a la Comunidad Autónoma, con la consiguiente delimitación entre las competencias estatales y autonómicas, incidiendo en el alcance de las primeras, lo que hemos reconocido al legislador estatal en los fundamentos jurídicos 7 y 8 . Sin embargo, es obvio que esa posible regulación normativa estatutaria no puede en ningún caso quebrantar el marco del art. 149.1 CE, desnaturalizando el contenido que sea propio de cada materia y que permite su recognoscibilidad como institución. Lo importante, en este sentido, es que el Estatuto de 
Autonomía, por ser norma de eficacia territorial limitada, si en ocasiones hubiere de realizar alguna precisión sobre el alcance de las materias de competencia estatal, lo haga para favorecer la mayor concreción de las competencias autonómicas que se correlacionan con ella y que, al hacerlo, no impida el despliegue completo de las funciones propias de la competencia estatal regulada en el art. 149.1 CE de que se trate. Sólo si se satisfacen estas exigencias, tal modo de proceder resultará acorde a la Constitución» (FJ 10).

Aún en este apartado, merecen destacarse algunos razonamientos que siguen el modo de operar señalado, o que obedecen a planteamientos preventivos. Así, al enjuiciar el art. 110.1 EAC, que define las competencias exclusivas de la Generalitat, el Tribunal declara que el Estatuto puede describir como consustanciales a aquéllas las potestades legislativa y reglamentaria, así como la función ejecutiva, cuyo ejercicio corresponde «únicamente» a la Generalitat. Pero a continuación matiza que «nada permite abonar la conclusión de que el Estatuto parte indefectiblemente del principio de que las competencias exclusivas se proyectan en todo caso sobre materias y no sobre sectores de una materia en la que puedan también incidir competencias exclusivas estatales». Se admite pues que el precepto estatutario «sólo se refiere al caso de la coextensión de la competencia y la materia in toto», pero ello no excluye la «eventualidad (...) de una exclusividad competencial referida únicamente a potestades normativas que cabe ejercer sobre un sector de la realidad en el que también concurren potestades exclusivas del Estado» (FJ 59).

Por otra parte, al enjuiciar el art. 111 EAC, relativo a las competencias compartidas, el Tribunal declara inconstitucional el inciso que define las bases «como principios o mínimo común normativo en normas con rango de ley» por cuanto «elevando a regla general una sola de las variables admitidas por el Tribunal en la definición del concepto de bases estatales, termina por definir el ámbito competencial del Estado» (FJ 60). Sin embargo, no valora la excepción contenida en el mismo precepto, cuando establece «excepto en los supuestos que se determinen de acuerdo con la Constitución y el presente Estatuto», lo cual se entiende que corresponderá determinar al legislador estatal.

En suma, la fundamentación de la STC 31/2010 conduce a la pérdida absoluta del valor del Estatuto, también para el juez constitucional, en la trascendental función de distribución competencial.

f) En cuanto a las relaciones institucionales, la Sentencia declara que el Estatuto «no es una sede normativa inadecuada para la proclamación de los principios que, como el de cooperación, han de inspirar el régimen de relaciones entre el Estado central y las instituciones de la Comunidad Autónoma catalana», si bien la concreta articulación de ese régimen debe responder a «exigencias estructurales de orden constitucional que, como es evidente, sólo pueden deducirse de la Constitución misma y, en consecuencia, de la jurisdicción que la interpreta». (FJ 110). Respecto a la participación de la Generalitat en las instituciones, organismos y procedimientos de toma de decisión del Estado que afecten a sus competencias «de acuerdo con lo establecido en el presente Estatuto y las leyes», el Tribunal entiende que no es contrario a la Constitución si se interpreta que este precepto genérico (art. 174.3 EAC) alude a «leyes estatales», salvando la titularidad de las competencias estatales, lo cual excluye que la participación se sustancie en la integración de órganos decisorios pero no en los de consulta y asesoramiento (FJ 111). Por otra parte, el precepto que establece la participación de la Generalitat en los procesos de designación de Magistrados del Tribunal Constitucional y de miembros del Consejo Ge- 
neral del Poder Judicial (art. 180 EAC) no se declara inconstitucional si se interpreta que «no afecta a la libertad del legislador estatal para hacer o no efectiva la voluntad de participación», y no "perjudica a la competencia del Estado para articular el modo en el que, dado el caso, dicha participación se inserte en los procesos de designación de los miembros de aquéllos órganos constitucionales» (FJ 113).

g) Por lo que hace a la financiación de la Comunidad Autónoma, la Sentencia declara que la competencia estatal sobre Hacienda general (art. 149.1.14 CE), la potestad originaria para establecer tributos mediante ley, exclusiva del Estado (art. 133.1 CE), y el papel del legislador orgánico en la regulación del ejercicio de las competencias financieras de la CCAA (art. 157.3 CE) determina que aquél «sea competente para regular (...) el marco general de todo el sistema tributario y la delimitación de las competencias financieras de las Comunidades Autónomas respecto de las del propio Estado». Los Estatutos pueden regular la Hacienda autonómica, y la Constitución garantiza la autonomía financiera de las CCAA, pero las decisiones relativas a la suficiencia financiera «han de adoptarse con carácter general y de forma homogénea para todo el sistema», y por ello deben tomarse en un órgano multilateral (el Consejo de Política Fiscal y Financiera) en el que el Estado ejercita las funciones de cooperación y coordinación, que deben integrarse con las de las Comisiones Mixtas de carácter bilateral, que pueden actuar con carácter previo o a posteriori.

\section{CONCLUSIONES}

De lo expuesto hasta aquí creo que pueden extraerse unas primeras conclusiones sobre la doctrina que contiene la STC 31/2010 en relación con la naturaleza y función del Estatuto de Autonomía como norma jurídica presente en el ordenamiento del Estado Autonómico. Como se ha visto, el Tribunal se ha pronunciado sobre esta cuestión a la vista de los planteamientos del recurso, y de las alegaciones de las partes, referidas al contenido posible del Estatuto de Autonomía.

Pues bien, a mi juicio la Sentencia ha deconstruido ${ }^{24}$ el acervo conceptual que ha sustentado hasta hoy la opinión mayoritaria de los juristas, y el mismo Tribunal Constitucional (STC 247/2007), sobre el cual se basaban las peculiares características del Estatuto como norma, y consecuentemente, la singularidad del mismo Estado de las Autonomías. Tales características hallaban su fundamento en una determinada comprensión de lo que se ha llamado la «Constitución territorial», y se basaban en algunas ideas: norma institucional básica, norma fundacional, carácter paccionado o confluencia de voluntades, bloque de la constitucionalidad, principio dispositivo, posición singular en el sistema de fuentes, especial rigidez, función delimitadora competencias, función interpretativa de la Constitución.

24 Utilizo la expresión «deconstrucción» por proximidad al concepto filosófico concebido por Jacques Derrida como una práctica orientada a arrojar sospechas sobre la totalidad de la tradición filosófica, proclamando que la tradición metafísica solo podrá ser superada si se «deconstruye» el lenguaje mismo de la filosofía. Ver LILLA, M., Pensadores temerarios, Debate, Madrid, 2004, págs. 141 a 163 
La fundamentación de la STC 31/2010 pone de manifiesto que el Tribunal ha establecido una doctrina sobre la naturaleza y posición del Estatuto que reduce drásticamente la función constitucional del Estatuto, marginando aquellas características que le conferían una singularidad como norma, lo que a su vez conduce a rebajar al mínimo su trascendencia en la configuración del Estado Autonómico. Especialmente llamativa resulta la doctrina en relación con una de las principales funciones constitucionales que desempeñan los Estatutos, la de atribución competencial, que el Tribunal deja prácticamente anulada al despojar de toda virtualidad al Estatuto dentro del bloque de la constitucionalidad, y basar la delimitación de competencias en las categorías constitucionales, expresión de la voluntad constituyente, que sólo el propio Tribunal es competente para su definición auténtica e indiscutible.

Como se ha señalado, después de la Sentencia el nuevo Estatuto de Cataluña ha quedado desactivado ${ }^{25}$ y aquélla pasa a ser un «manual de instrucciones» que va desactivando el contenido de muchos de sus preceptos, a los que sin embargo deja continuar formando parte del texto aprobado ${ }^{26}$. En su Voto particular el Magistrado Delgado Barrio señala con acierto que el Tribunal ha creado un «nuevo Estatuto», y mediante una técnica aparentemente de Sentencia interpretativa, ha convertido no pocos de sus preceptos en un «mero conjunto de pretensiones, propósitos, sugerencias o resúmenes de jurisprudencia» (Apartado 3).

Termino solo apuntando dos consecuencias que a mi parecer podrían derivarse de la nueva concepción del Estatuto sostenida en la Sentencia sobre el EAC 2006. La primera, que la doctrina sobre la naturaleza y función de los Estatutos afectará directamente a nuestro modelo de organización territorial. En la STC 247/2007 se afirmó que los Estatutos «constituyen una pieza esencial en la estructura compuesta del Estado» (FJ 5), mientras la STC 31/2010 mantiene una concepción del Estado Autonómico en el que los Estatutos, y lo que ellos aportan y suponen al sistema pierden parte de su papel hasta devenir prácticamente irrelevantes ${ }^{27}$. No cabe pues pensar en una futura evolución del sistema basada en una reforma estatutaria. La segunda, que esa nueva doctrina sobre la función constitucional del Estatuto afectará también a la misma naturaleza del Tribunal Constitucional, que se ha autoatribuido no solo en la STC 31/2010, si no pro futuro, una función de intérprete único, auténtico e indiscutible de la Constitución precisamente en el momento de su historia en que goza de menos auctoritas. Esta función casi constituyente, en caso de ejercerla, le alejaría ostensiblemente del papel normalmente reservado a la jurisdicción constitucional en una democracia constitucional.

$* * *$

25 Carrillo, M.: «Después de la sentencia, un Estatuto desactivado», El Cronista del Estado Social y Democrático de Derecho, núm. 15, 2010, pág. 26 y ss.

26 Tornos Mas, J., art cit. pág. 24. Así lo acreditaría la publicación de Pulido QueCEDO, M., El Estatuto de Autonomía de Cataluña. Anotado con la Jurisprudencia sistematizada de la STC 31/2010, de 28 de junio, AranzadiThomson Reuters, Pamplona, 2010

27 Albertí Rovira, E., art. cit, pág. 97. 
TITLE: The Statute after the Decision.

ABSTRACT: This article deals with the legal grounds sustaining the Decision of Spain's Constitutional Court (STC 31/2010, June 28) concerning the new Statute of Autonomy of Catalonia. In particular it focuses on the Court arguments on the nature and function of the statutes of autonomy, that is, on the limits of the content of the Statute. This is a crucial question for different reasons. Firstly, because the statutes of autonomy have an important role in the construction of the Spanish system of decentralization; secondly, because they are the feature that differentiates Spain's decentralized system from others. And thirdly, because such question grounded the very same appeal of unconstitutionality filed against the Catalonia's Statute and, as a consequence, is the central part of the Court's decision. The article is divided into three sections and some conclusions. First of all, the article explains the legal position of the parties involved in the process leading to the decision and shows how much these positions reflect different conceptions concerning the characteristics of the Statute of Autonomy. Secondly, it analyses the Court's legal reasoning in relation to the above-mentioned question: the potential contents of the statutes of autonomy are determined by the constitutional nature and functions of the statutes, from which some limits on the content can be derived. Thirdly, the article examines how the Court applies this latter criterion to judge some of the challenged sections. In this sense, the Court, in its decision, maintained the contents of challenged sections without declaring them unconstitutional. This is achieved by using the technique called «interpretative decision» but in an irregular way. The conclusion highlights that the legal grounds of the Court's decision on the nature and position of the statutes of autonomy have drastically reduced their constitutional function, marginalizing those characteristics that give them their distinctiveness as a law, and which in turn have also led to a reduction of the role the statutes of autonomy play in the configuration of the Spain's system of decentralization.

RESUMEN: Este trabajo analiza la fundamentación jurídica de la Sentencia del Tribunal Constitucional sobre el nuevo Estatuto de Autonomía de Cataluña (STC 31/2010, de 28 de junio) con el propósito de valorar la doctrina que contiene sobre la naturaleza y función de los Estatutos de Autonomía. Se trata de una cuestión de gran alcance porque se enfrenta a los limites materiales de una norma a la que la Constitución atribuye un papel esencial en la configuración de nuestro Estado de las Autonomías, y aquello que le confiere singularidad frente a otros modelos de organización territorial. Es asimismo la cuestión clave de la Sentencia, pues constituye la base sobre la cual se funda el conjunto del recurso de inconstitucionalidad: el ámbito material del Estatuto. El trabajo expone en primer lugar los planteamientos jurídicos de las partes personadas en el proceso, que reflejan distintas concepciones sobre las características normativas del Estatuto de Autonomía. En segundo lugar se analiza el razonamiento jurídico de la Sentencia sobre tal cuestión: el contenido posible de los Estatutos de Autonomía (FFJJ 4 y 5) viene determinado por su naturaleza (FJ 3) y su función constitucional (FJ 4), de los que se derivan unos límites cuantitativos y cualitativos a tal contenido (FJ 6). En tercer lugar se examina cómo el Tribunal aplica el criterio establecido en el anterior razonamiento para enjuiciar algunos de los principales preceptos impugnados. Ello se lleva a cabo mediante una operación que consiste en mantener el contenido de la práctica totalidad de los preceptos estatutarios impugnados sin declarar su inconstitucionalidad, utilizando de forma beterodoxa la técnica de las sentencias interpretativas. La conclusión pone de manifiesto que la fundamentación de la STC 31/2010 ha establecido una doctrina sobre la naturaleza y posición del Estatuto que reduce drásticamente su función constitucional, marginando aquellas características que le conferían una singularidad como norma, lo que a su vez conduce a rebajar al mínimo su trascendencia en la configuración del Estado Autonómico.

Key Words: Statute of Autonomy of Catalonia. Constitutional function. Decision of the Spain's Constitutional Court. Spanish system of decentralization.

Palabras Clave: Estatuto de Autonomía de Cataluña. Función constitucional. Sentencia del Tribunal Constitucional. Estado Autonómico.

FeCHA DE RECEPCIÓN: 28.12.2010. FeCHA DE ACEPTACIÓN: 26.01.2011 